\title{
On the taxonomic validity of Indian ground spiders: II. Genera Drassyllus Chamberlin, 1922 and Nodocion Chamberlin, 1922 (Araneae: Gnaphosidae)
}

\author{
Pradeep M. SANKARAN ${ }^{1, *}$, John T.D. CALEB $^{2} \&$ Pothalil A. SEBASTIAN $^{3}$ \\ ${ }^{1,3}$ Division of Arachnology, Department of Zoology, Sacred Heart College, \\ Thevara, Cochin, Kerala 682 013, India. \\ ${ }^{2}$ Zoological Survey of India, Prani Vigyan Bhawan, M-Block, New Alipore, \\ Kolkata, West Bengal 700 053, India. \\ *Corresponding author: pradeepmspala@rediffmail.com \\ 2Email: caleb87woodgate@gmail.com \\ 32Email: drpothalil@rediffmail.com

\footnotetext{
${ }^{1}$ urn:1sid:zoobank.org:author:0AEC69AA-7E17-401F-B83B-280C2F04AC6E

${ }^{2}$ urn:1sid:zoobank.org:author:2B3052EB-5000-4A94-8E38-F88CC308ECAD

${ }^{3}$ urn:Isid:zoobank.org:author:C22767DA-4C75-4685-B77E-2AB058C1091D
}

\begin{abstract}
Indian species of Drassyllus and Nodocion are revised, mostly based on the type material available in the National Zoological Collection, Zoological Survey of India, Kolkata. All the Indian representatives of the former genus are transferred to Cryptodrassus, with a synonymy of Drassyllus jabalpurensis syn. nov. with Cryptodrassus khajuriai comb. nov., while the Indian species of the latter genus are transferred to Setaphis, with a provisional transfer of Nodocion solanensis. All the examined type specimens are imaged and supplementary descriptions are provided.
\end{abstract}

Keywords. Cryptodrassus, Setaphis, transfer, type material, Zoological Survey of India.

Sankaran P.M., Caleb J.T.D. \& Sebastian P.A. 2020. On the taxonomic validity of Indian ground spiders: II. Genera Drassyllus Chamberlin, 1922 and Nodocion Chamberlin, 1922 (Araneae: Gnaphosidae). European Journal of Taxonomy 673: 1-14. https://doi.org/10.5852/ejt.2020.673

\section{Introduction}

This paper, the second in a series on the taxonomic validity of Indian ground spiders of the family Gnaphosidae Pocock, 1898, deals with the species described under the Holarctic genus Drassyllus Chamberlin, 1922 and the Nearctic genus Nodocion Chamberlin, 1922. The former genus includes five nominal species in India, viz. Drassyllus jabalpurensis Gajbe, 2005, Drassyllus khajuriai Tikader \& Gajbe, 1976, Drassyllus mahabalei Tikader, 1982, Drassyllus platnicki Gajbe, 1987 and Drassyllus ratnagiriensis Tikader \& Gajbe, 1976, whereas the latter has two species, viz. Nodocion solanensis Tikader \& Gajbe, 1977 and Nodocion tikaderi (Gajbe, 1993) (World Spider Catalog 2020). One Indian species from the latter genus, Nodocion mandae (Tikader \& Gajbe, 1977), has already been transferred 
to Setaphis Simon, 1893 and synonymized with Setaphis browni (Tucker, 1923) (Platnick \& Murphy 1996). All the Indian species of Drassyllus and Nodocion are known from the females only and are poorly described and illustrated, making their identification difficult. Moreover, the original illustrations of all these species are clearly differing from the generic features and female genital morphology of the type species of both genera, indicating the possibility of misplacement of Indian representatives under these genera. To clarify the taxonomic ambiguity on Indian species of Drassyllus and Nodocion and to make their identity more transparent, we examined the types of these species available in the National Zoological Collection, Zoological Survey of India, Kolkata and the results are presented below.

\title{
Material and methods
}

The specimens were studied under a Leica EZ4 HD stereo microscope. All measurements are in millimetres (mm). Lengths of palp and leg segments are given as: total (femur, patella, tibia, metatarsus (except for palp), tarsus). The micrographic images were taken with a Leica DFC500 digital camera attached to a Leica M205A stereo microscope with the software package Leica Application Suite (LAS, ver. 3.8) for stacking images taken at different focal planes.

\section{Abbreviations}

$\begin{array}{ll}\text { ALE } & =\text { anterior lateral eye } \\ \text { AME } & =\text { anterior median eye } \\ \text { PLE } & =\text { posterior lateral eye } \\ \text { PME } & =\text { posterior median eye } \\ \text { I-IV } & =1^{\text {st }} \text { to } 4^{\text {th }} \text { leg } \\ \text { NZC-ZSI } & =\text { National Zoological Collection, Arachnida Section, Zoological Survey of India, Kolkata }\end{array}$

\section{Results}

\author{
Class Arachnida Lamarck, 1801 \\ Order Araneae Clerck, 1757 \\ Family Gnaphosidae Pocock, 1898 \\ Genus Cryptodrassus Miller, 1943
}

Cryptodrassus khajuriai (Tikader \& Gajbe, 1976) comb. nov.

Figs 1-2

Drassyllus khajuriai Tikader \& Gajbe, 1976: 432, figs 5-8.

Drassyllus jabalpurensis Gajbe, 2005: 136, figs 23-27. Syn. nov.

Drassyllus khajuriai - Tikader 1982: 512, figs 490-494. — Gajbe 2007: 489, figs 208-212.

\section{Diagnosis}

Cryptodrassus khajuriai comb. nov. seems closely related to Cryptodrassus helvolus (O. PickardCambridge, 1872), as both have a large epigynal atrium. However, the former species can be distinguished from the latter by the following combination of characters: epigyne with anterior hood (epigyne of C. helvolus lacks anterior hood), highly coiled copulatory ducts with thick proximal and thin distal parts (copulatory ducts of $C$. helvolus less coiled and nearly uniform in diameter along the entire length) and globular receptacles (C. helvolus with nearly oval receptacles) (compare Figs 1C-D, 2C-D with Chatzaki \& Russell-Smith 2017: figs 5-6). 


\section{Material examined}

\section{Holotype of D. khajuriai}

INDIA • +; Madhya Pradesh, Jabalpur, rest house in Madla; 28 Feb. 1974; H. Khajuria leg.; NZC-ZSI, Kolkata 5043/18.

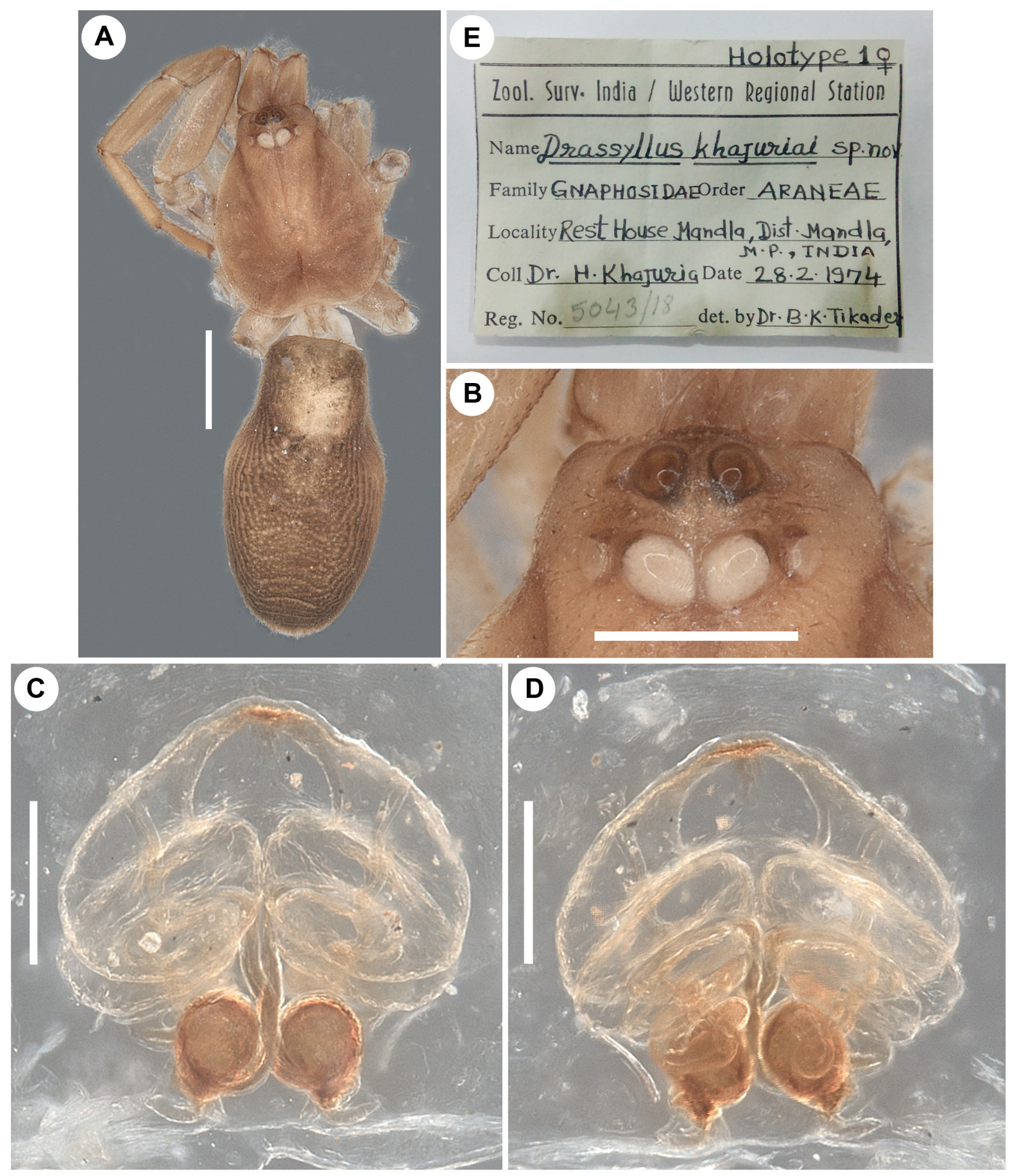

Fig. 1. Cryptodrassus khajuriai (Tikader \& Gajbe, 1976) comb. nov., , +, holotype of Drassyllus khajuriai Tikader \& Gajbe, 1976 (NZC-ZSI-5043/18). A. Habitus, dorsal view. B. Eyes of the same, dorsal view. C. Epigyne, ventral view. D. Same, dorsal view. E. Label from type bottle. Scale bars: A=1 mm; B = $0.5 \mathrm{~mm} ; \mathrm{C}-\mathrm{D}=0.2 \mathrm{~mm}$. 


\section{Holotype of $D$. jabalpurensis}

INDIA • ; Madhya Pradesh, Jabalpur, Bhirki Village on Jabalpur-Chargawan road; 24 Nov. 1970; D.K. Ghosal leg.; NZC-ZSI, Kolkata 5452/18.

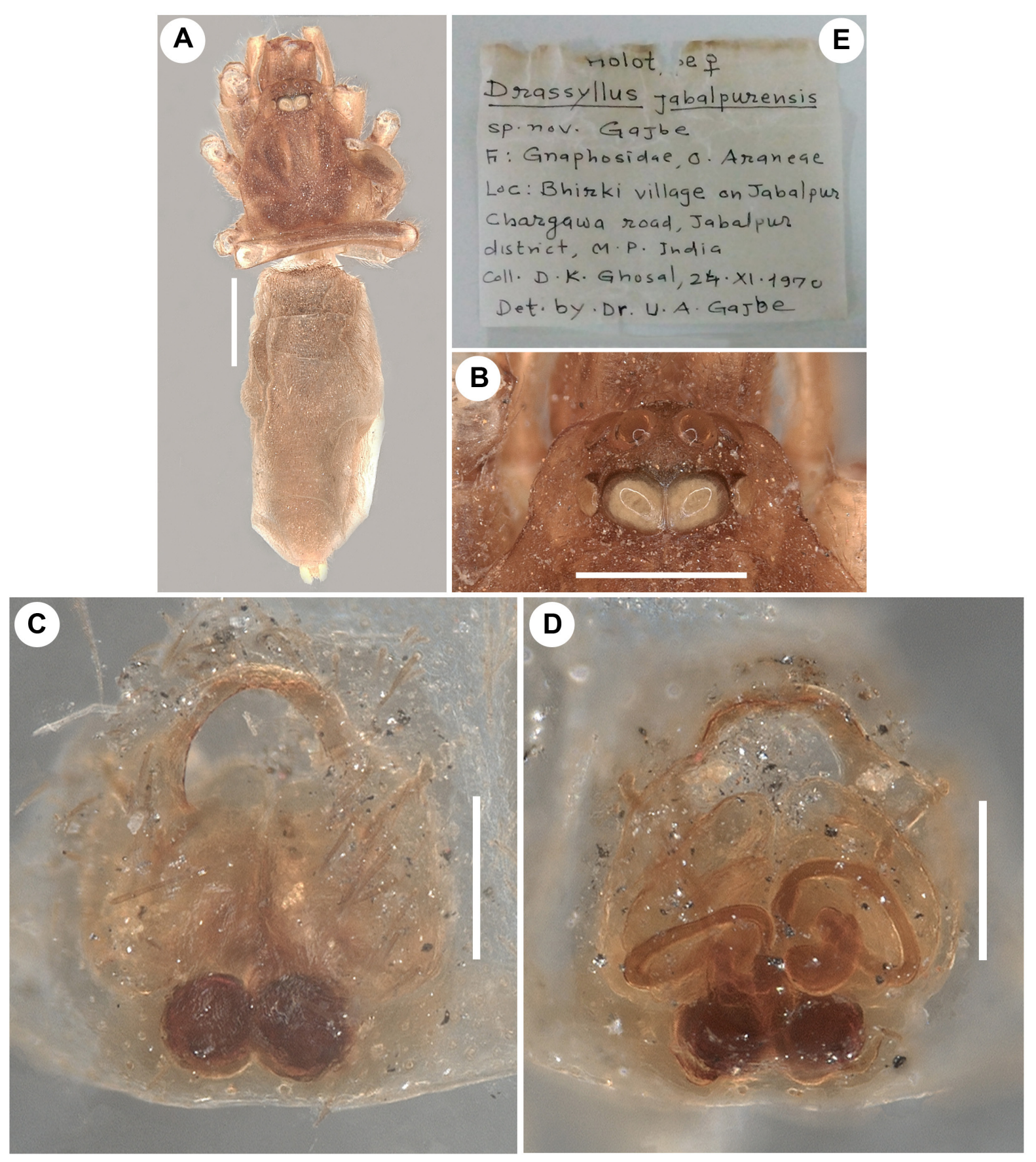

Fig. 2. Cryptodrassus khajuriai (Tikader \& Gajbe, 1976) comb. nov., $\uparrow$, holotype of Drassyllus jabalpurensis Gajbe, 2005 (NZC-ZSI-5452/18). A. Habitus, dorsal view. B. Eyes of the same, dorsal view. C. Epigyne, ventral view. D. Same, dorsal view. E. Label from type bottle. Scale bars: A=1 mm; $\mathrm{B}=0.5 \mathrm{~mm} ; \mathrm{C}-\mathrm{D}=0.2 \mathrm{~mm}$. 


\section{Supplementary description}

Female (holotype, Fig. 1)

Body length 5.38. Prosoma: length 2.18, width 1.76. Opisthosoma: length 3.20, width 1.71. Eye diameters: ALE 0.12, AME 0.13, PLE 0.11, PME 0.19. Eye interdistances: AME-AME 0.05, AMEPME 0.09, PME-PLE 0.04. Chelicerae length 0.67. Measurement of leg II 5.27 [1.51, 0.87, 1.03, 1.13, 0.73]. Epigyne (holotype, Fig. 1C-D): Epigynal plate moderately sclerotized, triangular, with smoothly triangular atrium with anterior hood (Fig. 1C). Copulatory openings indistinct. Copulatory ducts long, tubular, thick proximally and narrowed distally, obliquely twisted (Fig. 1D). Receptacles small, spherical, nearly contiguous, lying adjacent to posterior epigynal margin (Fig. 1D). Fertilization ducts narrow, diverging (Fig. 1D).

\section{Male \\ Unknown. \\ Justification of the transfer}

Tikader \& Gajbe (1976) described D. khajuriai on the basis of a female specimen collected in Madhya Pradesh. It resembles Drassyllus spp. only in the posterior median eyes, which are the largest and remaining contiguous in both Cryptodrassus and Drassyllus (see Murphy 2007: figs 184, 528; herein Fig. 1B). Detailed examination of the holotype of D. khajuriai revealed that it has all of the characteristic features of Cryptodrassus spp. as described and illustrated for Cryptodrassus hungaricus (Balogh, 1935), the type species of the genus (Murphy 2007: figs 528-529; Kovblyuk \& Nadolny 2010: figs 7-8), Cryptodrassus helvolus (O. Pickard-Cambridge, 1872) (Levy 1998: fig. 126; Chatzaki \& Russell-Smith 2017: fig. 5) and Cryptodrassus helvoloides (Levy, 1998) (Chatzaki \& Russell-Smith 2017: fig. 11): PMEs largest, irregular, all other eyes round, cheliceral promargin with three and retromargin with one tooth and epigyne with wide, anterior atrium. Considering these observations, we propose to transfer D. khajuriai to Cryptodrassus.

\section{Justification of the synonymy}

A detailed examination of the holotype of $D$. jabalpurensis shows that it has diagnostic features of D. khajuriai: triangular epigynal atrium with single anterior hood, highly coiled obliquely twisted copulatory ducts with thick proximal and narrow distal parts and spherical and contiguous receptacles (compare Fig. 1C-D with Fig. 2C-D). Based on these observations, we propose to consider D. jabalpurensis as a junior synonym of $D$. khajuriai.

\section{Remarks}

The ZSI collection has one glass bottle for D. khajuriai, labeled as 'holotype' (5043/18), containing a female specimen in fairly good condition, with only left leg II. The same bottle has a small glass vial containing the dissected epigyne. The ZSI collection has one glass bottle for D. jabalpurensis, labeled as 'holotype' (with no register number), containing a female specimen in bad condition. The same bottle has a small glass vial containing the dissected epigyne.

Cryptodrassus mahabalei (Tikader, 1982) comb. nov.

Fig. 3

Drassyllus mahabalei Tikader, 1982: 510, figs 485-489.

Drassyllus mahabalei - Gajbe 2007: 490, figs 213-217. 


\section{Diagnosis}

Cryptodrassus mahabalei comb. nov. resembles C. khajuriai comb. nov. in having a large, epigynal atrium and copulatory ducts with thick proximal and thin distal parts, but differs from the latter by the following combination of characters: epigyne with wide circular atrium (epigyne of $C$. khajuriai comb. nov. with triangular atrium), less coiled copulatory ducts (copulatory ducts of $C$. khajuriai comb. nov. highly coiled) and oval receptacles (C. khajuriai comb. nov. with globular receptacles) (compare Figs 1C-D, 2C-D with Fig. 3C-D).

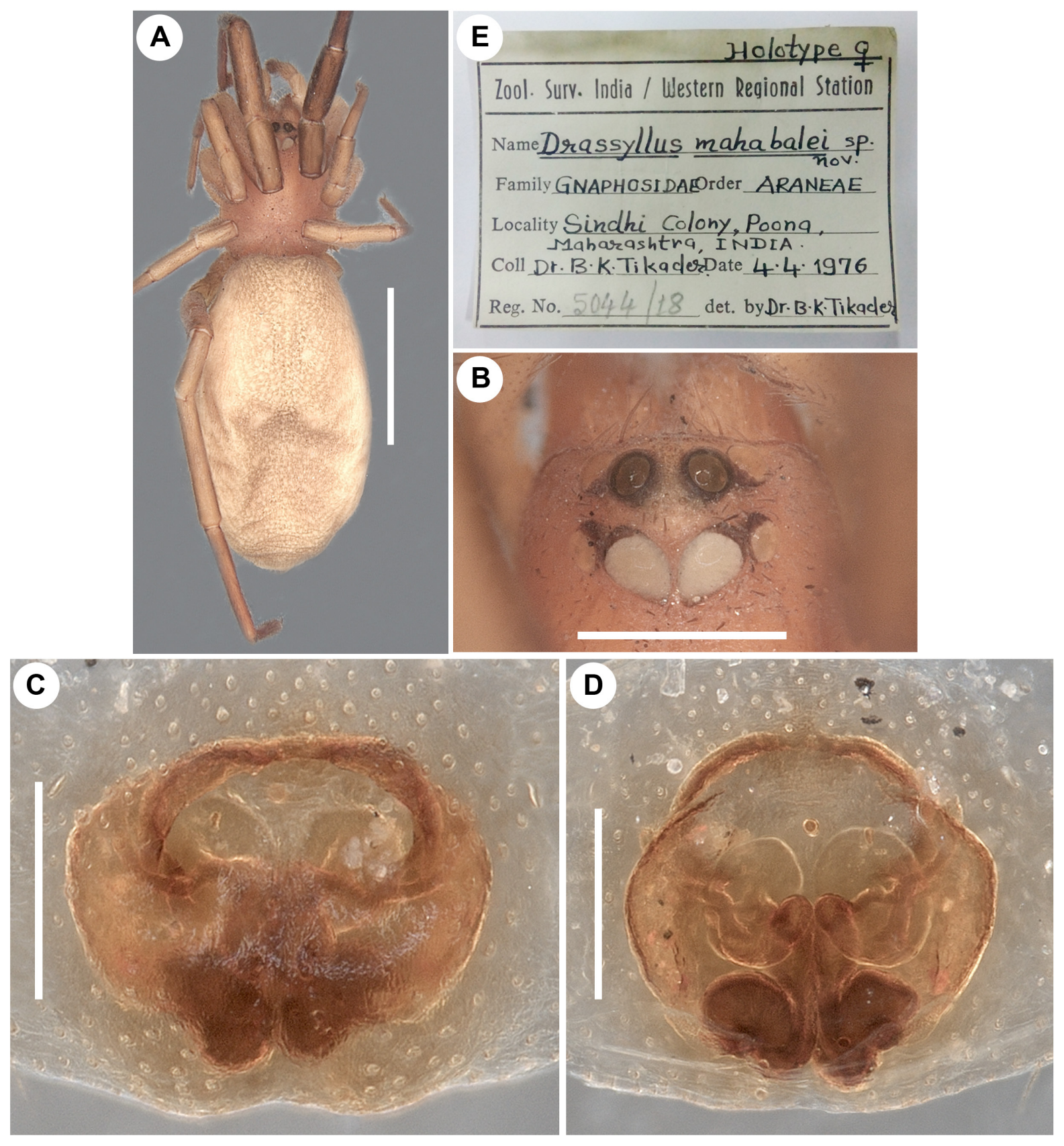

Fig. 3. Cryptodrassus mahabalei (Tikader, 1982) comb. nov., $\uparrow$, holotype of Drassyllus mahabalei Tikader, 1982 (NZC-ZSI-5044/18). A. Habitus, dorsal view. B. Eyes of the same, dorsal view. C. Epigyne, ventral view. D. Same, dorsal view. E. Label from type bottle. Scale bars: A= $2 \mathrm{~mm}$; B $=0.5 \mathrm{~mm}$; C-D = $0.2 \mathrm{~mm}$. 


\section{Material examined}

Holotype

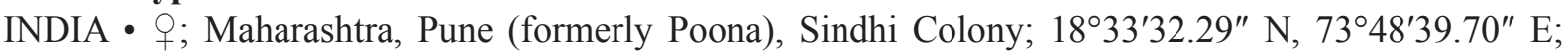
571 m a.s.l.; 4 Apr. 1976; B.K. Tikader leg.; NZC-ZSI, Kolkata 5044/18.

\section{Supplementary description}

Female (holotype, Fig. 3)

Body length 6.29. Prosoma: length 1.90, width 1.52. Opisthosoma: length 4.39, width 2.39. Eye diameters: ALE 0.12, AME 0.13, PLE 0.10, PME 0.17. Eye interdistances: AME-AME 0.06, AMEPME 0.09, PME-PLE 0.02. Chelicerae length 0.57. Measurements of palp and legs. Palp 1.82 [0.69, $0.34,0.26,0.53]$, I 6.01 [1.61, 0.94, 1.31, 1.25, 0.90], II 4.29 [1.17, 0.65, 0.80, 0.96, 0.71], III 3.92 $[1.03,0.58,0.71,0.99,0.61]$, IV 7.74 [1.97, 0.93, 1.69, 2.01, 1.14]. Leg formula: 4123. Palpal tarsus bears spines. Epigyne (holotype, Fig. 3C-D): Epigynal plate moderately sclerotized, nearly rectangular, with wide circular atrium with anterior hood (Fig. 3C). Copulatory openings indistinct. Copulatory ducts long, tubular, narrowed medially and thick distally, weakly twisted (Fig. 3D). Receptacles small, reniform, obliquely placed, lying adjacent to posterior epigynal margin (Fig. 3D). Fertilization ducts narrow, diverging (Fig. 3D).

\section{Male \\ Unknown.}

\section{Justification of the transfer}

Tikader (1982) described this species on the basis of a female specimen collected in Maharashtra. Like the former species, it has resemblance to Drassyllus spp. only in the posterior median eyes (Fig. 3B). A detailed examination of the holotype of $D$. mahabalei revealed that it has all of the characteristic features of Cryptodrassus spp. as noted in the case of previous species. Thus we propose to transfer D. mahabalei to Cryptodrassus.

\section{Remarks}

The ZSI collection has one glass bottle for this species, labeled as 'holotype' (5044/18), containing a female specimen in good condition, without right leg IV only. The same bottle has a small glass vial containing the dissected epigyne.

Cryptodrassus platnicki (Gajbe, 1987) comb. nov.

Drassyllus platnicki Gajbe, 1987: 289, figs 1-5.

\section{Type material}

Holotype (not examined)

INDIA - O; Maharashtra, Nagpur, Kachari Sawanga village/Kachari (sa) village; $21^{\circ} 11^{\prime} 41.53^{\prime \prime}$ N, 78³9'12.05" E; 448 m a.s.l.; 5 Mar. 1984; U.A. Gajbe leg.; NZC-ZSI, Kolkata 5144/18.

\section{Justification of the transfer}

Even though we did not examine the type of D. platnicki, which may either be lost or misplaced somewhere in the collection, this species agrees with Cryptodrassus spp. in generic features such as obliquely placed, large, contiguous PMEs, cheliceral promargin with three and retromargin with single tooth and epigyne with anteriorly placed atrium. All these indicate that this species in fact belongs to Cryptodrassus. The structure of vulvae of this species looks closely similar to the vulvae of $C$. khajuriai comb. nov., suggesting a possible synonymy of the former species with the latter one (compare 
Figs 1C-D, 2C-D with Gajbe 1987: figs 3-4); however, confirmation requires the examination of the type or topotype materials of C. platnicki comb. nov.

\section{Remarks}

We were unable to find the type of D. platnicki in the arachnid collection of ZSI, even though the author claimed that the type was deposited here (Gajbe 1987).

Cryptodrassus ratnagiriensis (Tikader \& Gajbe, 1976) comb. nov.

Fig. 4

Drassyllus ratnagiriensis Tikader \& Gajbe, 1976: 431, figs 1-4.

Drassyllus ratnagiriensis - Tikader 1982: 514, figs 495-499.

\section{Diagnosis}

Cryptodrassus ratnagiriensis comb. nov. can be distinguished from all other known species of Cryptodrassus by a disto-medially placed small, circular epigynal atrium and uniformly thick, C-shaped copulatory ducts that are confronting each other (Fig. 4C-D).

\section{Material examined}

\section{Holotype}

INDIA • क; Maharashtra, Ratnagiri, Chiplun, Kashedi Ghats; $17^{\circ} 54^{\prime} 14.77^{\prime \prime}$ N, $73^{\circ} 26^{\prime} 00.67^{\prime \prime}$ E; 386 m a.s.1.; 14 Feb. 1973; M. Babu Rao leg.; NZC-ZSI, Kolkata 5042/18.

\section{Supplementary description}

Female (holotype, Fig. 4)

Body length 8.58. Prosoma: length 2.77, width 2.43. Opisthosoma: length 5.81, width 3.07. Eye diameters: ALE 0.15, AME 0.16, PLE 0.14, PME 0.21. Eye interdistances: AME-AME 0.06, AMEPME 0.13, PME-PLE 0.04. Chelicerae length 0.87. Measurements of palp and legs. Palp 2.84 [1.08, $0.53,0.45,0.78]$, III 6.19 [1.69, 1.00, 1.17, 1.53, 0.80], IV 11.78 [3.27, 1.42, 2.75, 3.10, 1.24]. Palpal tarsus bears spines. Epigyne (holotype, Fig. 4C-D): Epigynal plate membranous, with circular atrium, with paired anterior hoods (Fig. 4C). Copulatory openings indistinct. Copulatory ducts short, thick, weakly twisted (Fig. 4D). Receptacles small, globular, contiguous, lying adjacent to posterior epigynal margin (Fig. 4D). Fertilization ducts narrow, diverging (Fig. 4D).

\section{Male \\ Unknown. \\ Justification of the transfer}

Tikader \& Gajbe (1976) described this species on the basis of a female specimen collected in Maharashtra. Like all the former species, this species also resembles Drassyllus spp. only in the posterior median eyes (Fig. 4B). A detailed examination of the holotype of D. ratnagiriensis revealed that its features fit those of Cryptodrassus spp. as noted for previous species. We therefore propose to transfer D. ratnagiriensis to Cryptodrassus.

\section{Remarks}

The ZSI collection has one glass bottle for this species, labeled as 'holotype' (5042/18), containing a female specimen in fairly good condition, with only left legs III and IV. The same bottle has a small glass vial containing the dissected epigyne. 

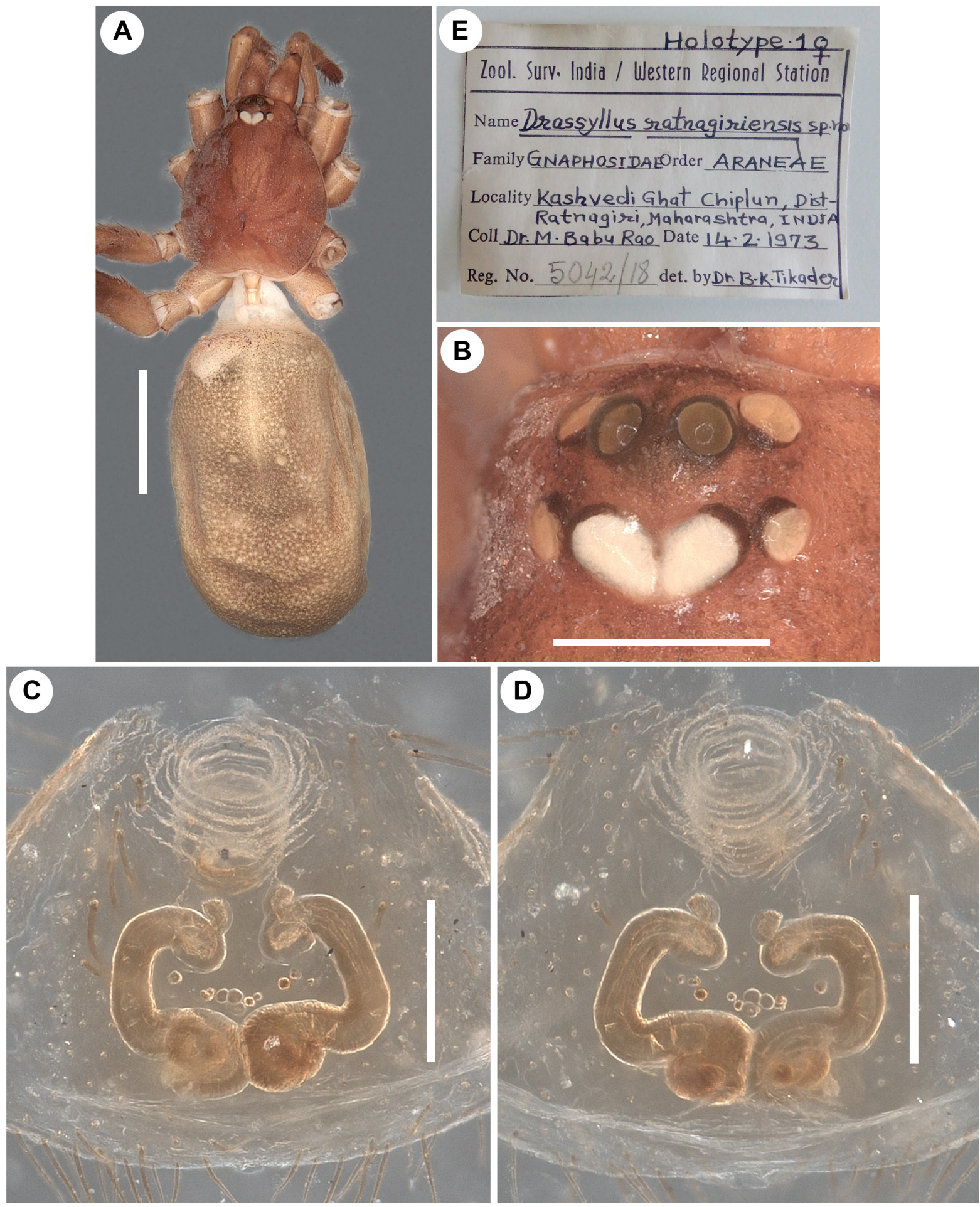

Fig. 4. Cryptodrassus ratnagiriensis (Tikader \& Gajbe, 1976) comb. nov., ㅇ, holotype of Drassyllus ratnagiriensis Tikader \& Gajbe, 1976 (NZC-ZSI-5042/18). A. Habitus, dorsal view. B. Eyes of the same, dorsal view. C. Epigyne, ventral view. D. Same, dorsal view. E. Label from type bottle. Scale bars: $\mathrm{A}=2 \mathrm{~mm} ; \mathrm{B}=0.5 \mathrm{~mm} ; \mathrm{C}-\mathrm{D}=0.2 \mathrm{~mm}$. 
Genus Setaphis Simon, 1893

Setaphis tikaderi (Gajbe, 1993) comb. nov.

Liodrassus tikaderi Gajbe, 1993: 247, figs 1-5.

Nodocion tikaderi Brignoli, 1983.

Liodrassus tikaderi - Gajbe 2007: 467, figs 120-124.

\section{Type material}

Holotype (not examined)

INDIA • 9 ; Madhya Pradesh, Jabalpur, Amjhar Ghati on Jabalpur-Dindori road; 27 Nov. 1965; H.P. Agrawal leg.; NZC-ZSI, Kolkata (no register number).

\section{Justification of the transfer}

Although we could not examine the type of L. tikaderi, this species agrees with Setaphis in generic features such as PME largest and irregularly rectangular, epigyne with anterior margins, epigynal midpiece surrounded by median ridges and highly twisted copulatory ducts (Platnick \& Murphy 1996). All these suggest that this species belongs to Setaphis. The original illustrations of the epigyne of this species show a close resemblance with that of S. browni in the shape of epigynal mid-piece, the path of internal ducts and the shape and orientation of the receptacles, indicating its possible synonymy with the latter species (compare Gajbe 1993: figs 3-4 with Fig. 6C-D). However, confirmation requires the examination of the type or topotype materials of $S$. tikaderi comb. nov..

\section{Remarks}

We found the holotype bottle of L. tikaderi in the arachnid collection of ZSI. However, it did not contain the holotype female; instead it contains a juvenile gnaphosid specimen, indicating that the holotype of L. tikaderi may either be lost or misplaced somewhere in the collection. We found the holotype bottle of Liodrassus mandae Tikader \& Gajbe, 1977 in the arachnid collection of ZSI (Fig. 6). The glass bottle, labeled as 'holotype' (5018/18), contains a female specimen in fairly good condition, with broken legs except the first pair. The same bottle has a small glass vial containing the dissected epigyne.

"Setaphis" solanensis (Tikader \& Gajbe, 1977) comb. nov.

Fig. 5

Nodocion solanensis Tikader \& Gajbe, 1977: 73, fig. 6A-D.

Nodocion solanensis - Tikader 1982: 456, figs 363-367.

\section{Diagnosis}

"Setaphis" solanensis comb. nov. resembles Setaphis subtilis (Simon, 1897) in having a large, flat proximal part of the copulatory ducts, but can be distinguished by the narrow, highly twisted distal part of the copulatory ducts (copulatory ducts of S. subtilis with broad, uncoiled distal part) (compare Fig. 5C-D with Platnick \& Murphy 1996: fig. 24).

\section{Material examined}

\section{Holotype}

INDIA • +; Himachal Pradesh, Solan, Kasauli (= Kasoli); 3054'04.64" N, 7657'53.55" E; $1817 \mathrm{~m}$ a.s.1.; 22 Dec. 1972; H.P. Agarwal leg.; NZC-ZSI, Kolkata 5002/18. 


\section{Supplementary description}

Female (holotype, Fig. 5)

Body length 7.54. Prosoma: length 2.97, width 2.20. Opisthosoma: length 4.57, width 2.77. Eye diameters: ALE 0.17, AME 0.16, PLE 0.16, PME 0.14. Eye interdistances: AME-AME 0.08, AMEPME 0.16, PME-PLE 0.12, PME-PME 0.08. Chelicerae length 0.90. Measurements of palp and legs. Palp (right) 2.97 [1.08, 0.53, 0.51, 0.85], III (right) 6.30 [1.78, 1.02, 1.23, 1.53, 0.74], IV 9.00 [2.32,

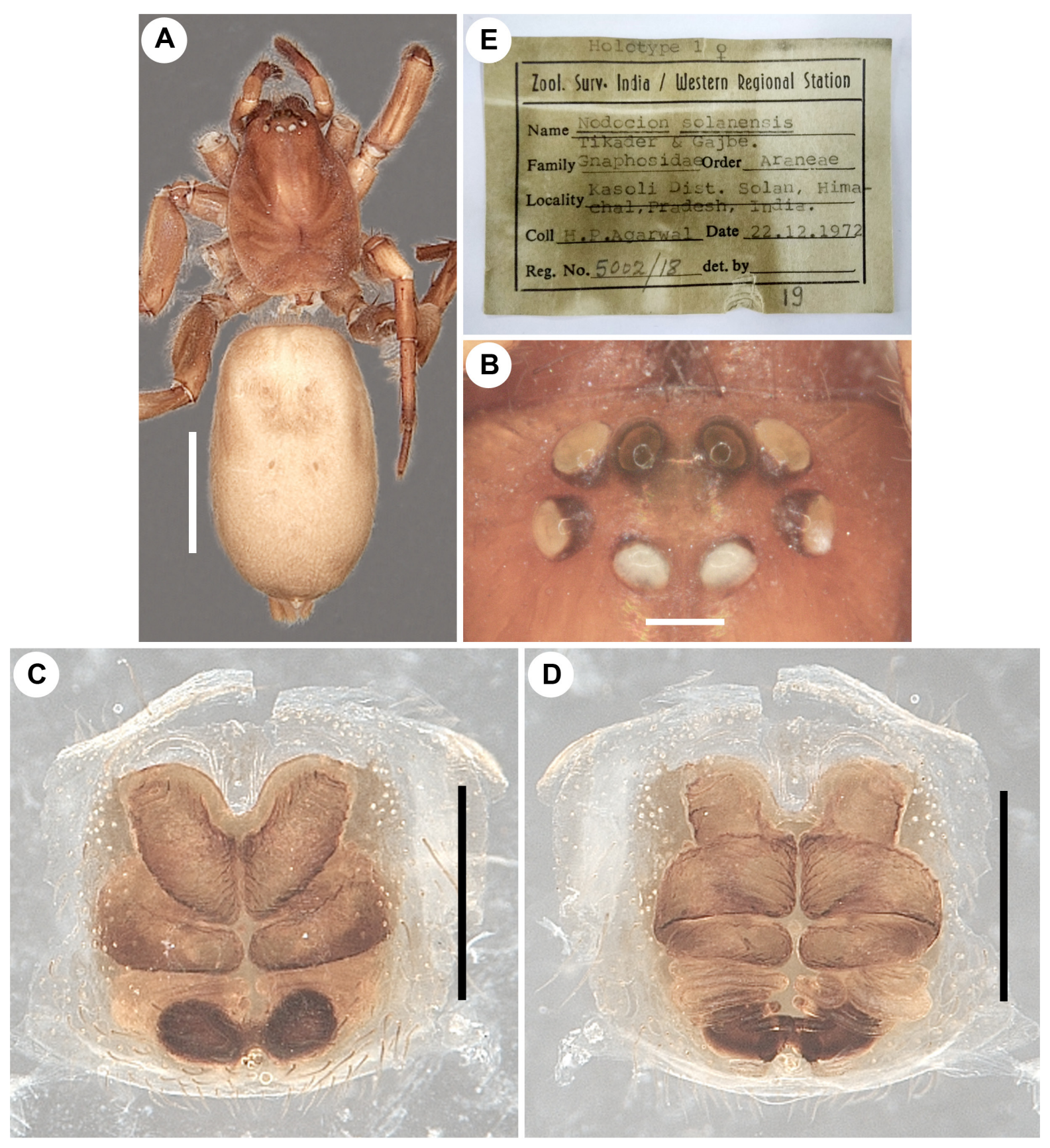

Fig. 5. "Setaphis" solanensis (Tikader \& Gajbe, 1977) comb. nov., $\uparrow$, holotype of Nodocion solanensis Tikader \& Gajbe, 1977 (NZC-ZSI-5002/18). A. Habitus, dorsal view. B. Eyes of the same, dorsal view. C. Epigyne, ventral view. D. Same, dorsal view. E. Label from type bottle. Scale bars: A = $2 \mathrm{~mm}$; $=$ $0.2 \mathrm{~mm} ; \mathrm{C}-\mathrm{D}=0.5 \mathrm{~mm}$. 
1.33, 2.01, 2.37, 0.97]. Epigyne (holotype, Fig. 5C-D): Epigynal plate sclerotized, with nearly M-shaped anterior ridge (Fig. 5C). Copulatory openings indistinct. Copulatory ducts long, highly twisted, with large, flat proximal part and narrow, tubular distal part (Fig. 5D). Receptacles small, oval, obliquely placed, diverging, lying adjacent to posterior epigynal margin (Fig. 5D). Fertilization ducts narrow, diverging.

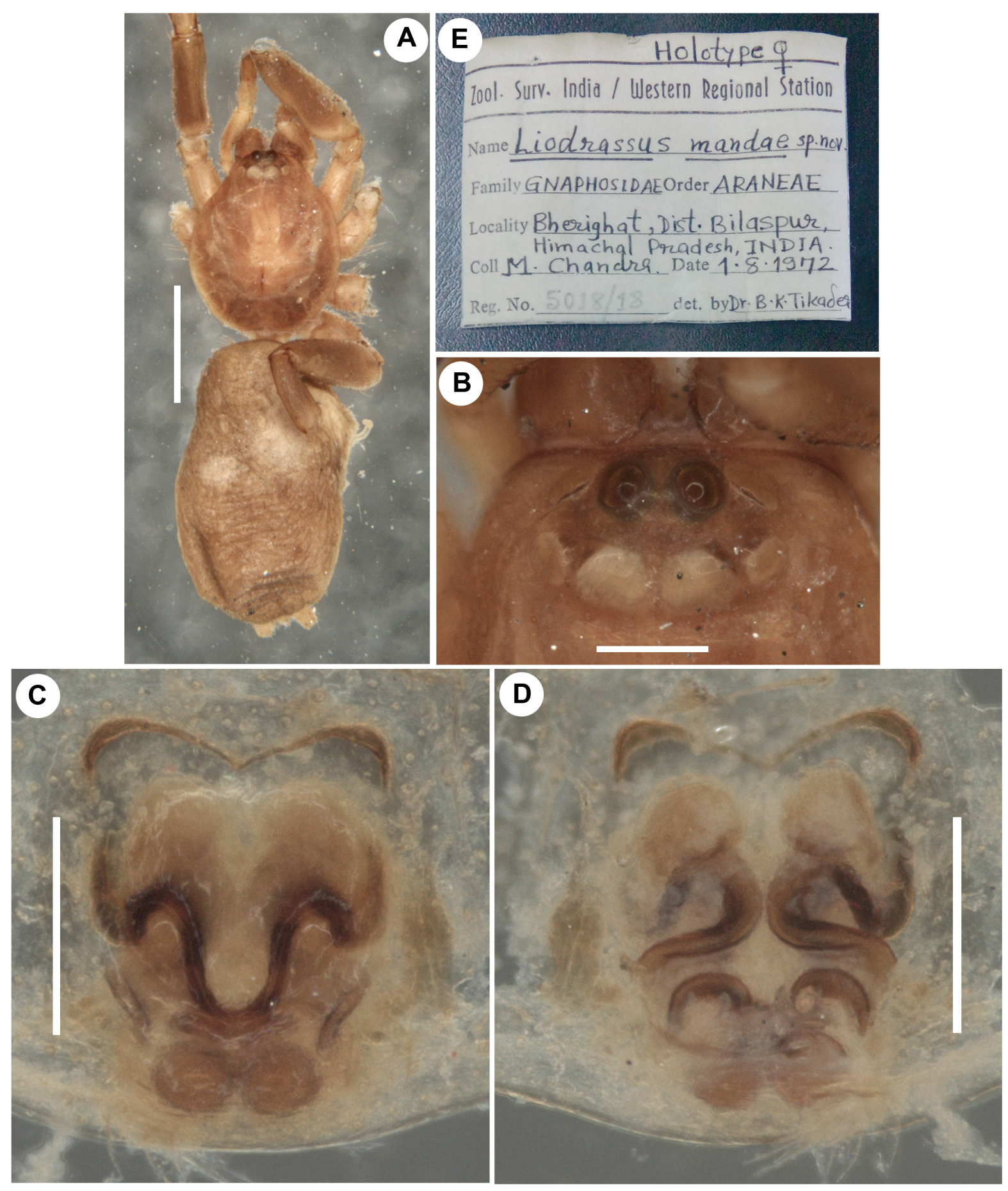

Fig. 6. Setaphis browni (Tucker, 1923), $q$, holotype of Liodrassus mandae Tikader \& Gajbe, 1977 (NZC-ZSI-5018/18). A. Habitus, dorsal view. B. Eyes of the same, dorsal view. C. Epigyne, ventral view. D. Same, dorsal view. E. Label from type bottle. Scale bars: A $=1 \mathrm{~mm}$; B-D $=0.2 \mathrm{~mm}$. 


\section{Male \\ Unknown. \\ Justification of the transfer}

Tikader \& Gajbe (1977) described this species on the basis of a female specimen collected in Himachal Pradesh. The original illustration of the epigyne of this species (Tikader \& Gajbe 1977: fig. 6b) clearly deviated from the epigyne of Nodocion mateonus Chamberlin, 1922 (Platnick \& Shadab 1980: figs 3-4), indicating its misplacement under Nodocion Chamberlin, 1922. Detailed examination of the holotype of $N$. solanensis revealed that its features do not fit those of any known gnaphosid genera, indicating that this species probably represents an unknown Indian gnaphosid genus. However, this will not be confirmed until the male pedipalp of this species will have been examined. Until then, we tentatively place this species in Setaphis due to the distant similarities in the following features: PMEs irregular, epigyne with a mid-piece and highly twisted internal ducts with wide proximal part (Fig. 5B-D).

\section{Remarks}

The ZSI collection has one glass bottle for this species labeled as 'holotype' (5002/18), containing a female specimen in fairly good condition, with broken legs and detached opisthosoma. The same bottle has a small glass vial containing the dissected epigyne.

\section{Discussion}

Even though the gnaphosid spiders described from India are numerically rich, the majority of them are known from poor descriptions and illustrations. A recent revision of the Indian species that had been attributed to the Nearctic genus Scopoides Platnick, 1989 clearly indicated the misidentification of Indian gnaphosid spiders (Sankaran et al. 2019). The present study provides further clarification to the taxonomy of the Indian gnaphosid fauna and strengthens the need of a thorough revision of all the known Indian gnaphosid spiders, in order to obtain clarity on the actual diversity of gnaphosid fauna in India.

\section{Acknowledgements}

We are grateful to Rev. Fr. Prasanth Palackappillil CMI, Principal, Sacred Heart College, Thevara, Cochin for providing all facilities for completing this work. We thank Dr Kailash Chandra, Director, Zoological Survey of India, Kolkata for giving access to the Arachnid Collection of ZSI, Shri. K. C. Gopi, former Additional Director, Zoological Survey of India, Kolkata and Dr Shelley Acharya, Officer-in-Charge, Arachnida Section for their support and to Mr Chandan Bera for his curatorial assistance. We thank two anonymous reviewers and Dr Rudy C.A.M. Jocqué (Royal Museum for Central Africa, Tervuren, Belgium), topic editor, for their constructive comments on an earlier draft of the MS that greatly improved it. The first and third authors especially acknowledge the Science and Engineering Research Board (SERB)-DST, New Delhi for providing funding support under the Major Research Project No. EMR/2015/002518.

\section{References}

Brignoli P.M. 1983. A Catalogue of the Araneae described between 1940 and 1981. Manchester University Press, Manchester.

Chatzaki M. \& Russell-Smith A. 2017. New species and new records of ground spiders (Araneae: Gnaphosidae) from Cyprus. Zootaxa 4329: 237-255. https://doi.org/10.11646/zootaxa.4329.3.3

Gajbe U.A. 1987. A new Drassyllus spider from India (Araneae: Gnaphosidae). Bulletin of the Zoological Survey of India 8: 289-290. 
Gajbe U.A. 1993. A new Liodrassus spider from India (Araneae: Gnaphosidae). Records of the Zoological Survey of India 91: 247-250.

Gajbe U.A. 2005. Studies on some spiders of the family Gnaphosidae (Araneae: Arachnida) from Madhya Pradesh, India. Records of the Zoological Survey of India 105: 111-140.

Gajbe U.A. 2007. Araneae: Arachnida. In: the Director, Zoological Survey of India (ed.) Fauna of Madhya Pradesh (including Chhattisgarh), State Fauna Series 15: 419-540. Zoological Survey of India, Kolkata.

Kovblyuk M.M. \& Nadolny A.A. 2010. Cryptodrassus hungaricus and Leptodrassex memorialis from Crimea (Aranei: Gnaphosidae). Arthropoda Selecta 19: 189-197.

Levy G. 1998. The ground-spider genera Setaphis, Trachyzelotes, Zelotes, and Drassyllus (Araneae: Gnaphosidae) in Israel. Israel Journal of Zoology 44: 93-158.

Murphy J. 2007. Gnaphosid Genera of the World. British Arachnological Society, St Neots, Cambridgeshire.

Platnick N.I. \& Murphy J.A. 1996. A review of the zelotine ground spider genus Setaphis (Araneae, Gnaphosidae). American Museum Novitates 3162: 1-23.

Platnick N.I. \& Shadab M.U. 1980. A revision of the North American spider genera Nodocion, Litopyllus, and Synaphosus (Araneae, Gnaphosidae). American Museum Novitates 2691: 1-26.

Sankaran P.M., Caleb J.T.D. \& Sebastian P.A. 2019. On the taxonomic validity of Indian ground spiders: I. Genus Scopoides Platnick, 1989 (Araneae: Gnaphosidae). Zootaxa 4648: 155-164. https://doi.org/10.11646/zootaxa.4648.1.8

Tikader B.K. 1982. Part 2. Family Gnaphosidae. In: The Fauna of India. Spiders: Araneae. Vol. II: 295-536. Zoological Survey of India, Calcutta.

Tikader B.K. \& Gajbe U.A. 1976. New spiders of Drassyllus from India (Gnaphosidae). Oriental Insects 10: 431-434.

Tikader B.K. \& Gajbe U.A. 1977. Taxonomic studies on some spiders of the genera Drassodes Westring, Haplodrassus Chamberlin, Geodrassus Chamberlin and Nodocion Chamberlin (family: Gnaphosidae) from India. Records of the Zoological Survey of India 73: 63-76.

World Spider Catalog. 2020. World Spider Catalog, ver. 21.0. Natural History Museum Bern. Available from http://wsc.nmbe.ch [accessed 15 Mar. 2020].

Manuscript received: 14 January 2020

Manuscript accepted: 27 March 2020

Published on: 24 June 2020

Topic editor: Rudy Jocqué

Desk editor: Kristiaan Hoedemakers

Printed versions of all papers are also deposited in the libraries of the institutes that are members of the EJT consortium: Muséum national d'histoire naturelle, Paris, France; Meise Botanic Garden, Belgium; Royal Museum for Central Africa, Tervuren, Belgium; Royal Belgian Institute of Natural Sciences, Brussels, Belgium; Natural History Museum of Denmark, Copenhagen, Denmark; Naturalis Biodiversity Center, Leiden, the Netherlands; Museo Nacional de Ciencias Naturales-CSIC, Madrid, Spain; Real Jardín Botánico de Madrid CSIC, Spain; Zoological Research Museum Alexander Koenig, Bonn, Germany; National Museum, Prague, Czech Republic. 